\title{
Interrelation between factor VII, prekallikrein, and hyperfibrinolysis in advanced cirrhosis
}

\author{
F VIOLI, C ALESSANDRI, D FERRO, MIRELLA SALIOLA, C CORDOVA, \\ A MUSCA, F BALSANO
}

From the Istituto di I Clinica Medica, University "La Sapienza" Rome, Italy

SUMMARY Factor VII and prekallikrein activities were studied in 37 patients with liver cirrhosis who were in a decompensated state. Sixteen of them died 30-70 days after admission; 21 survived and were discharged after 30-80 days. Seven who died and six survivors had signs of hyperfibrinolysis: factor VII activity differentiated the two groups independently of the presence of hyperfibrinolysis. The presence of hyperfibrinolysis significantly reduced prekallikrein activity, which did not differentiate clearly survivors from non-survivors. Long term follow up of survivors showed a good correlation between factor VII and prekallikrein activities with long term survival. Hyperfibrinolysis seemed to influence the clinical course of patients: $87 \%$ of patients with hyperfibrinolysis who died had fatal haemorrhagic episodes. Low factor VII activity may be a precursor of terminal liver insufficiency.

The prognosis of patients with liver cirrhosis is poor when accompanied by ascites, severe jaundice, haematemesis and prolonged prothrombin time. ${ }^{1}$ None of these signs, however, can be taken to indicate life expectancy of individual patients, ${ }^{2}$ or to predict imminent death. Prekallikrein (Prekk) and factor VII activities, two components of the intrinsic and extrinsic coagulation pathways, are sensitive markers of liver failure, when present in very low amounts.-5

Patients with liver cirrhosis, especially if decompensated, may have hyperfibrinolysis, which may be associated with low grade coagulation system activation $^{6}$ and can precipitate haemorrhagic episodes.? $^{7}$

\section{Material and methods}

Cirrhosis of the liver was diagnosed in 37 patients by liver needle biopsy in all but nine patients in whom the risks were too high. In these, diagnosis was based on the presence of the following signs: hepatosplenomegaly, ascites, jaundice, a serum albumin concentration of $30 \mathrm{~g} / 1$ and prothrombin activity of $40 \%$. The inclusion criteria for LC patients were the clinical and laboratory evidence of a decompensated state defined by the presence of at least two of the following signs: (i) ascites, (ii) encephalopathy associated with liver disease; (iii) a prothrombin activity of $40 \%$; (iv) a serum

Accepted for publication 28 July 1989 albumin concentration of $30 \mathrm{~g} / \mathrm{l}$; (v) and a serum bilirubin concentration of $68.4 \mu \mathrm{mol} / 1$. $^{7}$ Patients with acute hepatis, carcinoma of the liver, and with signs of endotoxaemia were excluded.

Sixteen patients died from liver insufficiency 30-70 days after admission. The remaining 21 survived and were discharged, on average after 30-80 days: they were followed up every six months to evaluate length of survival.

\section{BLOOD COAGULATION STUDY}

Blood samples were taken from patients who had fasted for at least 12 hours and mixed with $0.13 \mathrm{~mol} / \mathrm{l}$ sodium citrate (ratio 9:1). Normotest (Nyegaard \& $\mathrm{Co}$, Oslo) which determines the vitamin $\mathrm{K}$ dependent factors II, VII, and X, was performed on whole blood according to the manufacturer's instructions. Prekk plasma activity was evaluated by chromogenic substrate S-2302 (Kabi Diagnostics) using Cephotest (Immuno Diagnostics) as the Prekk activator. ${ }^{8}$ Intraand interassay coefficients of variation were 3 and $4 \%$, respectively. Factor VII plasma activity was evaluated by chromogenic substrate S-2222 (Kabi Diagnostics) as previously described.' Intra- and interassay coefficients of variation were 2 and $3 \%$, respectively. Plasminogen plasma activity was investigated by chromogenic substrate S-2251 (Kabi Diagnostics) as previously described. ${ }^{3}$ Alpha ${ }_{2}$-antiplasmin plasma activity was determined by Coatest Antiplasmin (Kabi Diagnostics). The end-point method was used to evaluate Prekk, factor VII, plasminogen and alpha ${ }_{2}-$ 
Table 1 Clinical and laboratory picture of patients with liver cirrhosis

\begin{tabular}{|c|c|c|}
\hline & $\begin{array}{l}\text { Survivors } \\
(n=21)\end{array}$ & $\begin{array}{l}\text { Non-survivors } \\
(n=16)\end{array}$ \\
\hline $\begin{array}{l}\text { Age (years) } \\
\text { Men } \\
\text { Women } \\
\text { Alcohol drinkers } \\
\text { Carriers of hepatitis B virus } \\
\text { Ascites } \\
\text { Liver encephalopathy } \\
\text { Previous haemorrhages } \\
\text { Mean (SD) serum albumin } \\
(\mathrm{g} / \mathrm{l}) \\
\text { Mean (SD) serum bilirubin } \\
(\mu \mathrm{mol} / \mathrm{l})\end{array}$ & $\begin{array}{r}44-80 \\
14 \\
7 \\
10 \\
6 \\
18 \\
7 \\
7 \\
\\
30 \quad(3.9) \\
71(23 \cdot 6)\end{array}$ & $\begin{array}{ll}41-73 & \\
13 & \\
3 & \\
6 & \\
6 & \\
16 & \\
9 & \\
8 & \\
& \\
27 \cdot 7 & (3 \cdot 6) \\
& \\
260 & (97 \cdot 6)\end{array}$ \\
\hline
\end{tabular}

antiplasmin activities. Fibrinogen was studied by the Schnitger and Goss coagulometer according to the method of Clauss. ${ }^{10}$ Fibrin degradation products were measured by Thombo-Wellcotest (Wellcome) using reference values of $\leqslant 10 \mu \mathrm{g} / \mathrm{ml}$ : patients with values higher than this were considered to have hyperfibrinolysis.

Each variable (Normotest, Prekk, and factor VII) reading was evaluated by using a two by two factorial analysis of variance in which the main effects were life or death outcome (VS) and presence or absence of hyperfibrinolysis (Hyper) according to the following model:

$$
\text { Reading = VS + HYPER + Interaction }
$$

Multiple comparisons using the $t$ test were done according to Bonferroni's method. ${ }^{11}$

A linear regression analysis of survival time was calculated in discharged patients by using length of survival and activity of clotting factors.

\section{Results}

The clinical and laboratory picture of those who survived and those who did not is summarised in table 1. The two groups were comparable with respect to age, sex, and clinical signs of cirrhosis; non-survivors had higher bilirubin values than survivors. Both groups had clinical history of haemorrhagic episodes (mostly melena and haematemesis); 21 survived and were discharged after 30/80 days.
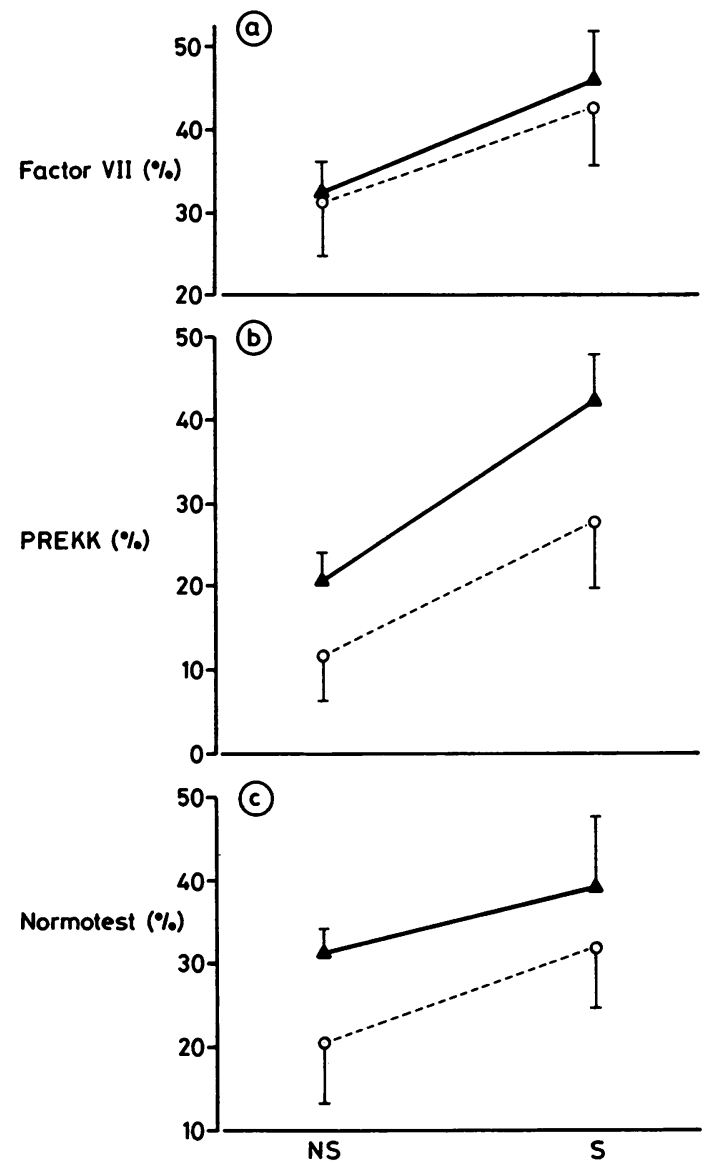

Figure Prothrombin activity (Normotest), prekallikrein (Prekk), and factor VII activities (\%) in surviving (S) and non-surviving (NS) patients with liver cirrhosis with $(\mathrm{O} \longrightarrow \mathrm{O})$ and without $(\boldsymbol{\Delta - \Lambda})$ hyperfibrinolysis.

Of those who died, seven died from gastrointestinal haemorrhage, six of whom were positive for fibrinogen degradation products.

Outcome and hyperfibrinolysis affected the serum activities of Prekk, and factor VII and Normotest results (table 2, figure). Patients who died from liver insufficiency had significantly lower values of Normotest (variance, 696.324; degree of freedom $=1$;

Table 2 Mean percentage values of Normotest results, prekallikrein, and Factor VII activities in survivors (S) and nonsurvivors (NS) with and without hyperfibrinolysis

\begin{tabular}{|c|c|c|c|c|c|c|}
\hline & \multicolumn{2}{|l|}{ Normotest } & \multicolumn{2}{|l|}{ Prekallikrein } & \multicolumn{2}{|l|}{ Factor VII } \\
\hline & $S$ & $N S$ & $\boldsymbol{S}$ & $N S$ & $S$ & $N S$ \\
\hline $\begin{array}{l}\text { With hyperfibrinolysis } \\
\text { Without hyperfibrinolysis }\end{array}$ & $\begin{array}{l}32 \cdot 5(n=6) \\
39 \quad(n=15)\end{array}$ & $\begin{array}{l}20 \cdot 8(n=7) \\
32 \cdot 2(n=9)\end{array}$ & $\begin{array}{ll}22 & (n=6) \\
38 \cdot 1 & (n=15)\end{array}$ & $\begin{array}{l}10 \cdot 7(n=7) \\
19 \cdot 6(n=9)\end{array}$ & $\begin{array}{l}43 \cdot 3(n=6) \\
46 \cdot 4(n=15)\end{array}$ & $\begin{array}{l}28 \cdot 5(n=7) \\
30 \cdot 3(n=9)\end{array}$ \\
\hline
\end{tabular}


Table 3 Multiple comparison results of mean values for clotting factors

Factor VII Normotest Prekallikrein

\begin{tabular}{|c|c|c|c|}
\hline \multicolumn{4}{|l|}{ Non-survivors: } \\
\hline Without hyperfibrinolysis & $30 \cdot 3 \%$ & $32.2 \%$ & $19 \cdot 7 \%$ \\
\hline $\begin{array}{l}\text { With hyperfibrinolysis } \\
\text { Survivors: }\end{array}$ & $28 \cdot 5 \%$ & & $10.7 \%$ \\
\hline $\begin{array}{l}\text { Without hyperfibrinolysis } \\
\text { With hyperfibrinolysis }\end{array}$ & $\begin{array}{l}46 \cdot 4 \% \\
43 \cdot 3 \%\end{array}$ & $\begin{array}{l}39 \% \\
32 \cdot 5 \%\end{array}$ & $\left.\begin{array}{l}38 \cdot 1 \% \\
22 \%\end{array}\right\} *$ \\
\hline
\end{tabular}

*p $<0.01$.

$F=16.46 ; p=0.0001$ ), Prekk (variance, 1816; degree of freedom $=1 ; F=72.65 ; p=0.0001)$, and factor VII (variance, 1950; degree of freedom $=1 ; \mathrm{F}=$ $80.59 ; p=0.0001)$. Hyperfibrinolysis significantly affected both Normotest (variance, 654; degree of freedom $=1 ; \mathrm{F}=15.48 ; \mathrm{p}=0.0005$ ) and Prekk (variance, 1291; degree of freedom $=1 ; F=51.65 ; p$ $=0.0001$ ), which were reduced compared with those of patients without hyperfibrinolysis. Factor VII activity, on the other hand, was not influenced by hyperfibrinolysis (variance, 47 , degree of freedom $=$ $1 ; F=1.98 ; p=0 \cdot 169$ ). Multiple comparison analysis by Bonferroni's method confirmed these results (table 3). Indeed, hyperfibrinolysis did not influence factor VII activity in survivors and non-survivors; a highly statistical difference was found between non-survivors without hyperfibrinolysis and survivors with hyperfibrinolysis. In non-survivors with hyperfibrinolysis Normotest results and Prekk activities were significantly lower compared with those without hyperfibrinolysis which also significantly reduced Prekk activities in survivors.

Low survivals were seen during follow up of discharged patients: seven died within the first year and eight within the second year. Cause of death was liver insufficiency $(n=9)$ and bleeding $(n=6)$. There was a good correlation between Prekk and factor VII activities and length of survival (Prekk: $r=0.899$; factor VII: $r=0.804, p<0.001)$.

\section{Discussion}

Length of survival in cirrhosis of the liver depends on the degree of liver insufficiency: compensated patients survive longer than those who are decompensated. ${ }^{2}$ The five year survival of decompensated patients is very low, reaching values of $34 \%$ when patients have ascites, jaundice, and haematemesis. ${ }^{2}$ The one year survival of our patients $(38 \%)$ is lower than that previously reported. ${ }^{1213}$ This is probably due to the inclusion criteria which selected patients with high degree of decompensation. Even if clinical data are useful to predict the prevalence of liver cirrhosis, the assessment of individual patients is very difficult. ${ }^{2}$ This is supported by our data which were comparable for survivors and non-survivors, except for much higher values of serum bilirubin in non-survivors.

The assessment of whether death in decompensated patients with cirrhosis is imminent is important in view of identifying patients as candidates for liver transplantation. Many coagulation factors, synthesised by liver cells, have been previously identified as markers of liver insufficiency. A previous study suggested that plasminogen, factor V, and factor XII were lower in non-survivors than in survivors, but these two subgroups were not clearly differentiated. ${ }^{14}$ Factor VII ${ }^{510}$ and Prekk ${ }^{515}$ activities were previously indicated as markers for the assessment of individual patients with acute as well as chronic liver disease. Because chronic liver disease can be complicated by hyperfibrinolysis, ${ }^{16}$ we studied the influence of this clotting abnormality on the prognostic value of factor VII and Prekk.

Our findings suggest that factor VII is a good prognostic indicator of liver failure whether or not patients had hyperfibrinolysis. Indeed, hyperfibrinolysis did not influence the factor VII activity in either group. The importance of factor VII as a prognostic indicator of liver insufficiency was particularly emphasised by the statistical difference between nonsurvivors without hyperfibrinolysis and survivors with hyperfibrinolysis. Prekk activity and Normotest results, on the other hand, did not differentiate survivors from non-survivors owing to the significant reduction in their activity caused by hyperfibrinolysis. Prekk activity could be a useful marker of liver insufficiency in long term follow up, however. Prekk and factor VII activities were significantly correlated with the length of survival of discharged patients.

The clinical course of inpatients was complicated by fatal haemorrhagic episodes predominantly in patients with hyperfibrinolysis. This could therefore ${ }^{17}$ precipitate haemorrhagic episodes, probably through the consumption of blood clotting factors. The identification of the mechanisms leading to hyperfibrinolysis could be useful for the future management of cirrhosis of the liver.

We are grateful to Dr Cucchi Paolo for the statistical analysis of the results and to Mrs Caterina Guzzo for help with the manuscript.

\section{References}

1 Sherlock S. Chronic hepatitis and cirrhosis. Hepatology 1984; $4: 25 s-8 s$.

2 Vierling JM. Epidemiology and clinical course of liver disease: identification of candidates for liver transplantation. Hepatology 1984;4:845-945.

3 Cordova C, Musca A, Violi F, et al. Prekallikrein behaviour in chronic active hepatitis and in cirrhotic patients. Haemostasis 1984;14:218-22.

4 Green G, Poller L, Thompson SM, Dymock IW. Factor VII as a 
marker of hepatocellular synthetic function in liver disease. $J$ Clin Pathol 1976;29:971-5.

5 Cordova C, Violi F, Alessandri C, et al. Prekallikrein and factor VII as prognostic indexes of liver failure. Am J Clin Pathol 1986; 85:579-82.

6 Cordova C, Violi F, Alessandri C, Musca A, Balsano F. Low doses of calcium-heparin in liver cirrhosis. Thromb Haemostas 1985; 54:551.

7 Franco D, Durandy Y, Deporte Y, Bismuth H. Upper gastrointestinal haemorrhage in hepatic cirrhosis: causes and relation to hepatic failure and stress. Lancet 1977;i:218-20.

8 Cordova C, Violi F, Alessandri C, Ferro D, Saliola M, Balsano F. Hageman factor, high molecular weight kininogen, and prekallikrein in chronic liver disease. J Clin Pathol 1986;39:1003-5.

9 Mariani G, Di Nucci GD, Avvisati G, Corrao D. Synthetic substrate in haemostasis testing. Boca Raton: CRC Press (in press).

10 Clauss A. Geriunungsphysiologische schnellmethode zur bestimmung des fibrinogens. Acta Haematol 1957;17:237-40.

11 Morrison DF. Multivariate statistical methods. Kogakusha: McGraw Hill, 1976.

12 Saunders JB, Walters JRS, Davies P, Paton A. A 20 year prospective study of cirrhosis. Br Med J 1981;282:263-6.

13 D'Amico G, Morabito A, Pagliaro L, Marchini E. Survival and prognostic indicators in compensated and decompensated cirrhosis. Dig Dis Sci 1983;31:468-75.

14 Biland L, Duckert F, Prisender S, Neman D. Quantitative estimation of coagulation factors in liver disease. The diagnostic and prognostic value of factor XIII, factor $\mathrm{V}$ and plasminogen. Thromb Haemostas 1978;39:645-56.

15 Dymock JK, Tucher JS, Woolf IL, Poller L, Thompson JM. Coagulation studies as a prognostic index in acute liver failure. Br J Haematol 1975;29:385-95.

16 Francis BB Jr, Feinstein DI. Clinical significance of accelerated fibrinolysis in liver cirrhosis. Haemostasis 1984;14:460-6.

17 Bertaglia E, Belmonte P, Vertolli V, Azzurro M, Martines D. Bleeding in cirrhotic patients: a precipitating factor due to intravascular coagulation or to hepatic failure. Haemostasis 1983;13:328-35.

Requests for reprints to: Professor F Violi, Istituto di I Clinica Medica, Policlinico Umberto I University of Rome, Italy. 